\title{
COMENTARIO BIBLIOCRÁLCO
}

\section{Ma Ángeles Marcos García CIBIO \\ marcos@ua.es}

RACHEL LOUISE CARSON, 2001. Primavera silenciosa. Crítica, Barcelona, 229 páginas.

Silent Spring vio la luz por vez primera en 1962 y desde entonces no ha cesado de impresionar a sus lectores. Este libro representó una de las mas tempranas y decididas denuncias del daño que el empleo indiscriminado de productos químicos utilizados contra las plagas estaba ocasionando en el medio ambiente desde finales de la Segunda Guerra Mundial. A partir de entonces fue cuando los plaguicidas químicos de origen natural, fueron drásticamente sustituidos por nuevos productos orgánicos de síntesis de mayor toxicidad debido a que destruyen enzimas protectoras de organismos, bloquean procesos de oxidación biológica necesarios para la obtención de energía e impiden el normal funcionamiento de los seres vivos. En la actualidad la fecha de su publicación representa no sólo un hito, sino el pistoletazo de salida en la lucha contra la agresión química del medio ambiente. Su autora (1907-1964) mediante datos tan verídicos como espeluznantes, va describiendo un panorama desolador en el que se pone claramente en evidencia la pérdida de biodiversidad que se está produciendo en diversos ecosistemas tanto acuáticos como terrestres y los graves problemas de salud que se detectan en Norteamérica de manera alarmante debido a las aplicaciones masivas de productos químicos utilizados principalmente en el control de plagas y malezas.

Gracias al éxito y rápida difusión de Silent Spring, la acusación de esta Zoóloga estadounidense empezó a tener eco tanto en la población, para la que este libro supuso una vía definitivamente eficaz de denuncia, como en los colectivos preocupados por la Conservación del Medio, a los que a partir de entonces resultó mas fácil obtener una respuesta favorable por parte de los organismos políticoadministrativos de Estados Unidos con responsabilidad en la Conservación del Medio, Salud Pública y Mejora de la Calidad de Vida. La denuncia hecha por Raquel Carson hace ya 40 años es, a pesar de la reacción que causó en Norteamérica, totalmente vigente ya que la aplicación incontrolada o injustificada de productos biocidas sigue todavía acallando las voces anunciadoras de la primavera en muchos lugares del planeta.

La edición traducida al castellano, aunque con una terminología entomológica poco cuidada, nos facilita la comprensión histórica de este problema y anima a seguir trabajando en el perfeccionamiento y puesta a punto de nuevos métodos biológicos y parabiológicos de control de plagas que lleguen a ser una alternativa o un complemento eficaz a la lucha química. Como se recoge en el libro en palabras del biólogo canadiense G.C. Ullyett: Debemos cambiar nuestro modo de pensar, abandonar la aptitud de superioridad bumana $y$ admitir que en muchos casos encontramos en el medio ambiente, el modo de limitar las colonias de seres vivos nocivos de un modo mas económico que el aplicado por nosotros.
Rachel L. Carson

Primavera silenciosa

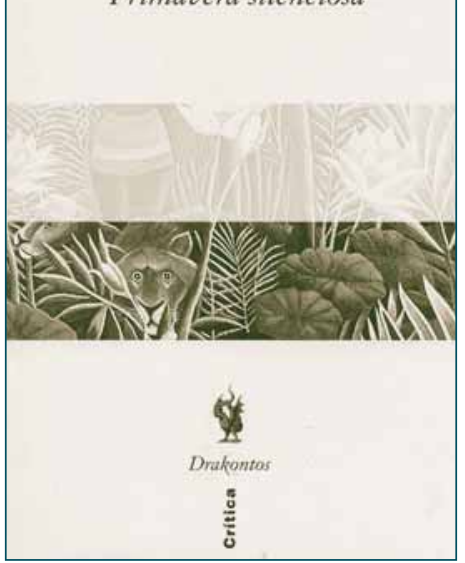

